\title{
Critical Importance of Emphasising Working- Class Parents in Digital Inclusion: A US Latino/ a Case Study
}

\begin{tabular}{cl}
\hline Cláudia Silva & $\begin{array}{l}\text { Madeira Interactive Technologies Institute } \\
\text { (M-ITI), Portugal } \\
\text { claudia.silva@m-iti.org }\end{array}$ \\
Corresponding Author \\
Adolfo R. Mora & $\begin{array}{l}\text { Department of Communication, Schreiner } \\
\text { University, USA } \\
\text { amora@schreiner.edu }\end{array}$ \\
Joseph D. Straubhaar & $\begin{array}{l}\text { The University of Texas at Austin, } \\
\text { Department of Radio Television and Film } \\
\text { (RTF), USA } \\
\text { jdstraubhar@austin.utexas.edu }\end{array}$ \\
& \\
\hline
\end{tabular}

In this article, we draw on extensive qualitative data to analyse the specific case of a digital inclusion program launched by the non-profit organisation River City Youth Foundation, located in Central Texas. The case is particularly interesting because the organisation, which is primarily a youth centre, realised they needed to start including parents in their programs in order to achieve their first and foremost institutional goal: to increase the number of low-income youth in US colleges. For this study, we use Pierre Bourdieu's theories of capital to analyse how the organisation integrates education in their digital inclusion program - called ¡TechComunidad! - and thus how they instil techno-dispositions and cultural capital about how US education works in parents of children in kindergarten to 12th grade (K-12). This case is also relevant because it is related to a specific community of low-income Latino immigrants, mostly of Mexican descent, who live in a neighbourhood, where most of the residents are

Silva, C., Mora, A.R., Straubhaar, J. (2018). Critical importance of emphasizing working-class parents in digital inclusion: a U.S. Latino/a case study. The Journal of Community Informatics, 14(1), 183--205.

Date submitted: 2018-10-01. Date accepted: 2018-10-15.

Copyright (C), 2018 (the author as stated). Licensed under the Creative Commons AttributionNonCommercial-ShareAlike 2.5. Available at: www.ci-journal.net/index.php/ciej/article/view/1453 
Hispanic. The ¡TechComunidad! program may take between six and eight weeks, and at the end of the training, grants participants a Chromebook - a laptop with a Google OS that only works with internet connectivity. Our results suggest that the organisation managed to instil techno-dispositions and knowledge of education, but parents may still face other sorts of divides, once they bring their Chromebook home.

\section{Introduction}

The purpose of this article is to analyse the specific historical case of the Texan nonprofit organisation River City Youth Foundation (RCYF) that, in order to strengthen its focus on youth ${ }^{1}$, decided to include parents in the process of digital inclusion. This, we argue, addressed the digital divide from one of its major sources: homes that have no broadband access to the internet, and parents with an undeveloped techno-capital and little awareness of the importance of both education and technology skills for children growing up in a high-tech economy such as Austin, in the United States of America.

This non-profit organisation operates in a large working-class Latino neighbourhood, mostly of Mexican descent, in a Texas city with a rapidly growing technology economy: Austin, Texas. Specifically, between 2008 and 2012, more than 43 thousand people were estimated to live in this neighbourhood, and about 14 thousand of its residents had children younger than 17 years old. The ethnic composition of the area is primarily Hispanic (roughly 77\%), and among them, less than a third $(30 \%)$ were foreign-born whose nationality can be traced to Latin and Central America (97\%). Whereas the city annual income was on average 53 thousand dollars, the median income was far below at an estimated \$43, 375 (Austin Chronicle, 2014).

About 15 years ago, one of the main leaders of the organisation, realised that a major problem for its youth was that the parents ${ }^{2}$ in some immigrant low-income communities did not understand the increasing importance of education in general for the US workforce (Musel-Guilley, personal communication, March 2014). On top of this, many working class parents were not aware of the place of technology in the workforce for the US in general and even less so for the economy of Austin, Texas, which sees itself as a Technopolis - a city whose economy focuses on recent technological developments and industries (Straubhaar, Spence, Tufekci \& Lenz, 2012).

We are aware that 'youth' holds pejorative meanings and may be deemed offensive for some, as it is regularly associated with negative realities such as 'at risk youth' or 'disaffected youth'. In this article, however, we adopt the language used by the organisation studied herein, as it defines itself as a 'youth centre.' We also use it in the sense provided by the Oxford dictionary: 'The period between childhood and adult age,' which refers also to $\mathrm{K}-12$.

2 Although the overwhelming majority of these parents are mothers, in this article we adopt the organisation's language, which does not regard gender but parenthood in general. For this reason, we use the term 'parents' or 'parent-students' to refer to ¡TechComunidad! participants. 
This observation led the organisation to launch the digital inclusion program iTechComunidad!. ${ }^{3}$ The program is important to study because it focuses on both youth and their parents. Although the organisation is called a youth centre, the directors of the RCYF, Mona Gonzales and Oné Musel-Guilley, also started focusing heavily on adults who are caregivers of schoolchildren, for specific reasons examined throughout this case study. We consider this an interesting case that merits extra consideration given the current global digital divide, where new social divides related to knowledge and disposition (Bourdieu, 1984) are emerging and others are persistent (more in the next section).

We relied on qualitative data that was collected between 2012, when ;TechComunidad! was launched, and Spring 2016 to contribute to discussions about the digital divide. The data emerged mainly from the long, five-year relationship that the lead author had with the organisation in different roles: volunteer, researcher and instructor. Although we used fieldnotes, interviews, and also written stories, we took a special interest in the lessons given to ;TechComunidad! participants for us to better speculate what technodisposition was deemed appropriate for US Latinos to navigate the Technopolis in which they resided. We were particularly interested in what skillsets and desires about information and communication technologies (hereafter, ICTs) were shaped by the organisation.

In this article, we begin with a discussion of the global digital divide, then we proceed to discuss the role of community technology centres in addressing and bridging the digital divide. Afterwards, we present our theoretical framework based on the theories of capital by Pierre Bourdieu (1984). Then, our conversation shifts to the qualitative methods used, including the history of ;TechComunidad!, followed by discussion and conclusions.

\section{Global Digital Divide}

Briefly, the digital divide refers to the gap between those who have or do not have internet access as well as the skills and knowledge to operate ICTs (Norris, 2001; Gonzales, 2016). Generally, debates are still around structural issues such as inequalities in access to the internet and computers (first level) and use of ICTs (second level). Along these lines, recent studies have found persistent gaps in terms of physical access to technology among poor communities (Gonzales, 2016) or that 'digital divide access is here to stay' (Hilbert, 2016).

Gonzales' (2016) findings provide support and extend the theory of technology maintenance by emphasising a shift in the US digital divide from issues of ownership to issues of sustainability. In her study with 72 low-income participants, Gonzales found 'that nearly all used the internet, but technology maintenance practices were widespread, including negotiation of temporarily disconnected service, broken hardware, and logistic limitations on public access' (2106, p. 1). Similarly, Büchi, Just \& Latzer (2016) provides evidence that internet access does not correspond to equal

\footnotetext{
3 See http://rivercityyouth.com/events/techcomunidad/
} 
usage, and thus the authors confirm the existence of a second-level divide in highpenetration countries such as the United States of America, New Zealand, Sweden, Switzerland and United Kingdom.

With not so positive findings, Hilbert argues that, while 'the digital divide in terms of subscriptions is rapidly closing, the digital divide in terms of bandwidth is rapidly evolving and here to stay' (2016, p. 12). For Hilbert, it is urgent to develop indicators to track the digital divide in terms of bandwidth (Hilbert, 2016).

A number of studies have observed that even as access divides begin to narrow, divides in disposition (Straubhaar et al., 2012) and attitudes (Tondeur, Sinnaeve, Van Houtte \& van Braak, 2011; Lutz, 2016), knowledge (Balboni 2007; Ginossar \& Nelson, 2010; Radovanović, 2011), skills (van Dijk, 2006), participation (Hargittai \& Walejko, 2008) and capabilities (Cunningham 2009; lalorek, 2016) may be holding constant or even growing.

Despite the current discourse about technological revolutions, inequality in terms of technology access is still a reality, as past research has found that new technologies benefit those who already have access to other resources than those with fewer resources (van Dijk, 2006). In the next section, we discuss the active role of technology community centres in addressing the digital divide.

\section{Community Technology Centres}

Community technology centres (hereafter, CTCs) provide classes and access to ICTs as well as internet connectivity for neighbourhood residents who otherwise do not have these (or face limited) resources at home (Lentz et al., 2012; Servon \& Nelson, 2001). Like public libraries, some of these centres remain open after school hours and on the weekends in order for students and parents to complete and continue their school and homework tasks that require online submissions or specialised computer software. In fact, low-income parents and other adults go to such sites mostly or exclusively for their internet connectivity and computer use, even if the access is slow and the technology old (Dixon et al., 2014; Strover et al., 2015). CTCs are especially valuable due to their fostering of techno-capital, a form of cultural capital that is related to the knowledge of, and access to, technology, especially in a way that is personally useful (Straubhaar et al., 2012; Lu \& Straubhaar, 2014, McConnell, 2014). Techno-capital is usually achieved through general and short-term classes about how the internet operates, how computers work, online storage opportunities, open-source or other software, and e-mail (Straubhaar et al., 2012). Those who complete these ICT courses, typically adults, have reported a better understanding of word-processing programs, e-mail, or search engines (Dúran, Dúran, Perry-Romero \& Sanchez, 2001; Machado-Casa, Sánchez \& Ek, 2014; Rivera, 2008). Their success is partly due to the leaders of CTCs listening to the needs of the communities they serve (Rivera, 2008). At least in the case of digitally excluded Latinos, as in the case in our research, CTCs recognise the linguistic barriers and family dynamics that hinder a successful integration of ICTs at home. CTCs in Latino neighbourhoods offer ICT classes in Spanish (whether partially or entirely if the instructor is bilingual) and often provide services like childcare during classes. 
The learning environment of the learners in CTCs presents challenges to what technocapital can be developed. Not all centres have desktop computers, and teaching occurs through laptops or tablets, which means the learning is usually restricted to one device not across devices. Instructors might not be bilingual, placing non-English speakers at a disadvantage if lesson delivery is in English. The location of CTCs might not be within walking distance, adding an extra expense for commuters who take public transportation. Not all those participating in classes are beginners, therefore making introductory classes irrelevant to them. Parent-students might not have a media broker at home (Katz, 2010), because they live alone, or children are not of age to help them navigate ICTs. Classes may only be offered on a morning or evening basis, which means people with typical working hours have difficulty attending morning classes.

River City Youth Foundation, where the iTechComunidad! took place, defines itself as a 'youth and technology center' with seven core areas including 'community development' and 'college and career' (RCYF, n.d.). The iTechComunidad! program targets parents instead of youth and offers two sessions, in the morning (10 a.m. to noon) and the evening (6 p.m. to 8 p.m.). Parents who attend the evening class may bring their children, who are integrated into other programs of the organisation. Students are granted a Google Chromebook upon graduating the training, which has been offered as a six- or eight-week class depending on availability of instructors and holidays in the calendar.

\section{Theoretical Framework and Research Questions}

Structural factors have often been found to explain the digital divide, because ethnic, gender, and income groups are seen as either 'haves' or 'have nots' regarding the access to broadband and mobile internet in addition to owning computers and smartphones (Lopez, Gonzalez-Barrera \& Patten, 2013; Strover et al., 2015; Tsei \& Rains, 2017). It seems to some that closing the gap is as simple as having internet access and ownership of digital devices, since so many policy programs still focus on access, yet the picture is more complex than this. Culture and social networks are also key in determining who adopts and uses the internet and what significance is placed on ICTs ( $\mathrm{Lu} \&$ Straubhaar, 2012; Straubhaar et al., 2012). Having friends who can help with troubleshooting devices or translating websites and growing up in households that recognise the benefits of computers in social mobility and creativity are some examples where relationships and culture shape people thinking and attitudes toward ICTs.

Recently, Bourdieu's (1984) capital framework has been useful in explaining many aspects of the relationship between culture and technology. Among the capitals are social (i.e., such as networks of friends to learn from), economic (e.g., wealth to buy connectivity and devices), and cultural (e.g., taste, knowledge of how to use computers and the internet); each is separate but can be converted to another.

Theoretically, this article focuses on two extrapolations from Bourdieu's concept of the capitals (1984). We build on some work that expands on his ideas of disposition and cultural capital. Disposition is a set of attitudes and orientations that we learn initially from our parents, from those in our neighbourhood, from peers, school, etc. Cultural 
capital is the useful skills, ideas and knowledge we learn first from our parents and then schools, peers, work, etc. that we have extrapolated into an idea of technology specific capital or techno-capital, that we learn from those same sources. Disposition interacts closely with capital. If our parents, peers and neighbours do not seem to think something is important, then we are probably less interested in learning it (Bourdieu, 1984). We are building on work that extrapolates disposition into techno-disposition (Rojas et al., 2004 ), the orientation we develop about whether technology access and skills are important to us. The development of a techno-disposition is not a given in working class Latino communities, where children may not know many adults working with technology (Rojas et al., 2012).

Our interest was in the lessons provided to parent-students through ;TechComunidad! so they were able to grasp what is important for them to know about the internet and computers in the cultural context of the neighbourhood. We also looked at the extrapolation of cultural capital into technological capital, or techno-capital, to see what techno-capital seemed most relevant and useful to these parents. We looked closely at the curriculum strategy for imparting both an increased techno-disposition as well as focusing on what is perceived to be the most important general capital (like the importance of education for their children) and the techno-capital that is most relevant to parents trying to help their children in both general and technological education (such as learning how to communicate with teachers via email and how to use the schools district's website for monitoring their children's progress in school). Eventually, we continued the scholarly work on techno-capital and techno-dispositions by conceptualising further what ICT orientations CTCs prioritise in teaching parents residing in a homogeneous ethnic neighbourhood. As such, we addressed the following research questions:

RQ1: How does ;TechComunidad!, as part of a CTC, incorporate learning about ICTs and education into its curricula?

RQ2: What is the impact of focusing on parents as well as youth in the overall ¡TechComunidad! program?

\section{Methods}

This study took the case study as a method (Yin, 1989) with an ethnographic approach to offline participant observation. This study was part of a research project on the community computer-training program of ;TechComunidad! that spanned several years (2012-2016). The lead author conducted extensive ethnographies, including working first as a volunteer, and then as doctoral researcher, and later on as a teacher and administrator in the program. During the latter period, the organisation was aware that the researcher, who was a graduate student at The University of Texas at Austin, was conducting observations for research purposes. This role of being an instructor allowed the researcher, who speaks English and Spanish, to collect fieldnotes and conduct informal interviews during that period. This is to say that the relationship and rapport of the researcher with the organisation and community was built over time and with care. 
We used other qualitative data about the organisation. Some data came from the participant observations and interviews conducted by undergrad students who were taking a course on technology and culture, offered by one of the authors, in East Austin. We also analysed the lesson plans of iTechComunidad!, hard copies of which (both in English and Spanish) were given to parent-students in a binder. One class assignment was included in the analyses too. It was a written assignment that parents turned in for extra credit and involved them interviewing another parent-student in ¡TechComunidad!. Our data sources are discussed in more detail below.

Yin (1989) presents participant observation as a major strategy in developing case studies. Case studies are of most benefit when the researcher takes active roles in their research instead of being a passive observer. Among the advantages of this technique are: gaining access to events or groups that are otherwise inaccessible to scientific investigation; the ability to perceive reality from the viewpoint of someone 'inside' the case study rather than external to it; and the other opportunities for data collection that arise as the investigator has the ability to manipulate events or situations. The lead author of this study took such a role in this study. First working as a volunteer and assisting with the teachings of the non-profit organisation in 2012 and 2013 and later as the lead instructor in 2015 and 2016, while also being the person in charge of selecting parent-students and conducting community outreach occasionally in 2016. This study had approval from the Institutional Review Board (IRB) from the University of Texas at Austin, where this research was conducted. Participants' privacy was ensured through the use of pseudonyms. The directors of the non-profit organisation RCYF provided written consent for the disclosure of their own names as well as the organisation's name in this article.

\section{Data Sources and Data Analysis}

\section{Curriculum Analysis}

The curriculum of ;TechComunidad! can unfold within six or eight weeks. Regardless of its overall length, there are four sets broken into subsets of lessons, which MuselGuilley $^{4}$ prepared. Although instructors are generally not allowed to change the curriculum, the first author had some freedom during her time as lead instructor to add examples for clarification purposes. It is important to say that we did not analyse the curriculum of all years since iTechComunidad! started. Rather we analysed the curriculum that started in 2014, when the organisation integrated Chromebooks and cloud computing into its training (Figure 1). Briefly, the lessons had ICT terminologies and step-by-step instructions, followed by assignments related to the content taught. Lesson Set 1 was about using email for education purposes. The lessons taught parents basic terms (e.g., email sender, inbox and sent email, compose button), and how to set up a Gmail account using a Chromebook. Lesson Set 2 (2.1, 2.2, 2.3) was about the internet and its benefits, including a brief history of the internet and basic terminology (e.g., URL, search engine, domain, bookmark, scroll bar, cloud computing and types of

4 The director and founder of the program ¡TechComunidad! has extensive experience in leading educational programs across the United States of America, working as a consultant. 
websites). Lesson Set 3 taught parents how to monitor their children's grades online. And finally, Lesson Set 4 (4.1, 4.2, 4.3, 4.4) was dedicated to Google Apps (e.g., how to use Google Calendar, Google Drive, Google Docs, video and image searching, Google Play store, app launcher, terms such as 'chromie'). We conducted a thematic analysis of the curriculum, looking for a logical order in the lessons (Figure 1). Our analysis was guided by how the organisation incorporated education into its computer training, in response to community need.

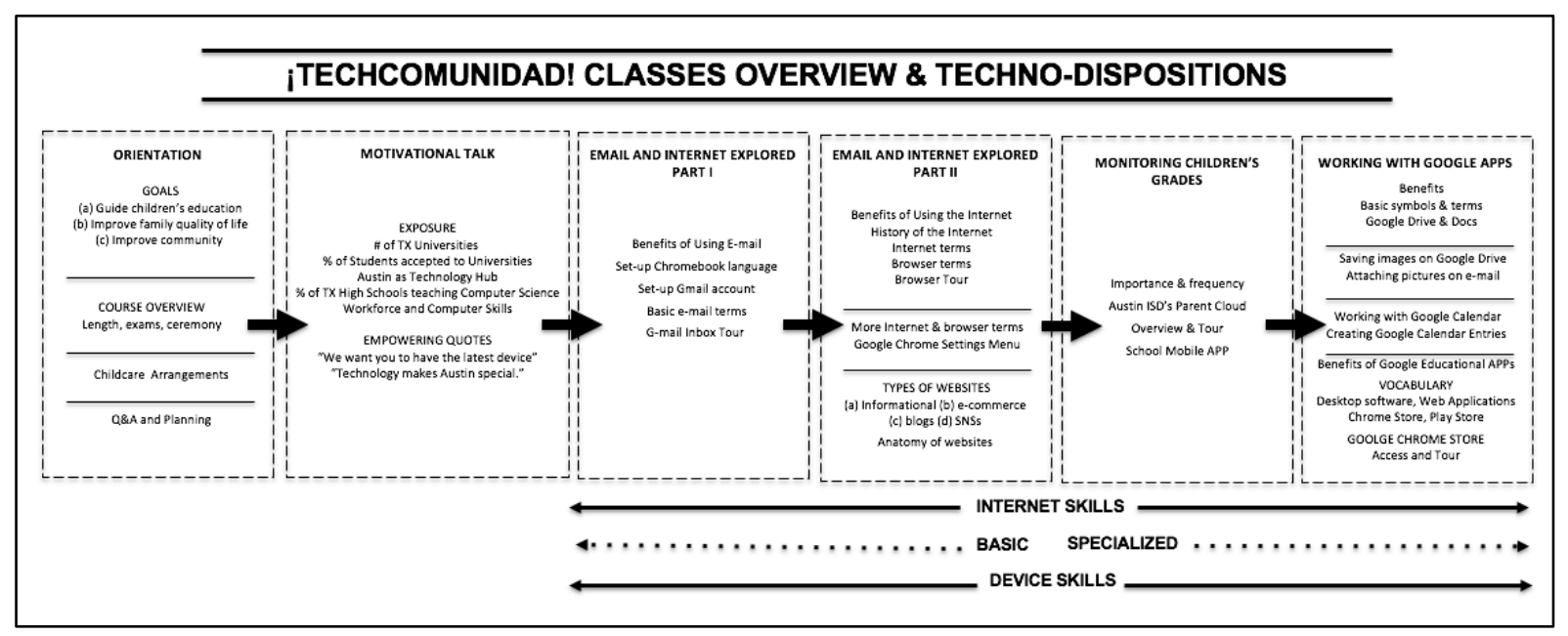

Figure 1. Steps and Lessons encompassing TechComunidad.

\section{Extra-Credit Project Stories}

More data came from typed assignments that ;TechComunidad! parents turned in close to the end of the course. The assignment helped participants gain extra credit or to make-up a mandatory course requirement (e.g., attendance). As an incentive for completing the project, parents were automatically entered in a special draw at their graduation ceremony. The instructions generally read: 'You will need to use your Chromebook and the organisation's computer lab to complete the project.' MuselGuilley, the founder and manager of ;TechComunidad!, came up with these assignments and its steps.

Parents had two options for their extra-credit project. Option one was to attend a youth class, write an article (blog) in Google Docs about what the class was working on, and email the story to the organisation manager. Parents were told that their article could be used on the organisation and on the program websites. The document must contain the following: 'Your name as the author, 3 photos you take of the class in action, A summary of the project students are working on, An article that is 400 or more words long.'

Option two was to "write an article (blog) in Google Docs about the journey of one of your ;TechComunidad! classmates as they have completed the course. You will need to set up a time to interview your classmate outside of class. You may use the organization computer lab to conduct your assignment. Email the story to the organisation manager. 
The article document must contain the following: "Your name as the author, 1 photo you take of your classmate in the RCYF'S computer lab, A summary of what your classmate has learned in the class and what their plans are for using their new knowledge and in moving forward with their new Chromebook, An article that is 400 or more words long."”

We only used the second option in this article, because it dealt with the topic of digital inclusion directly and was from the perspective of the parents. We included their stories as a means of supporting what techno-dispositions were learnt through quotes and experiences. The parents' names were changed to project their identities.

\section{Our Case Study: the digital inclusion program ;TechComunidad!}

iTechComunidad! came to be in the Fall of 2012 as a response to the lack of awareness among low-income parents about technology, education, the city economy, and the work force. The aim of the program was to enable parents to:

1. Guide their children's education from pre-K to college and career

2. Improve the quality of life for their family

3. Improve the community around them.

The computer training did not stop in supplying parent-students the skills and knowledge about handling ICTs, but it also granted them a (Chromebook) device after completing classes. In so doing, ;TechComunidad! tried to address the first and second digital divides. The creator of iTechComunidad! did not want to create a digital inclusion program without a device giveaway. The program starts with a Kick-off oneday event, in which very big white tents are installed at the organisation site. The creator of iTechComunidad! called this one-day event 'mobilization day.' The families were selected ahead of time and they need to have an event packet with an invitation ticket in order to participate in this event. The parents were required to take their children, if they are a 'mother' or 'father', and their spouses to this event. (Grandparents with charge of children were also included.) The event was a strategy to inspire and engage the families with technology. Spanish- and English-speaking parents were organised into different groups to facilitate the training with bilingual instructors. Parents had to undertake two activities: (a) an email scavenger hunt, and (b) to create a visual mural with collages responding the question, 'How do you want to guide your children's education?'

The organisation aimed to have about 100 families on site during its one-day event. Parents and children were split into different groups, and each cluster was further divided by age. The participants were exposed to basic computer tasks such as emailing and using search engines, and they also had to create a visual board, expressing their goals to improve their families. 
After this event, attendees were surveyed via telephone to see the best time and shifts for sessions. Once the schedule was made by the organisation, the classes began. Parents could partake of this program by either coming to sessions in the morning or in the evenings for four hours divided into two lessons each week. These sessions lasted about six weeks or eight weeks, as the time frame was contingent on many factors such as weather, holidays, and the learning curve.

Musel-Guilley, the founder of ;TechComunidad! believes the program creates bonding. She says, 'This program is very special, because there is a bond. We make it feel safe for parents. When they go to take other computer classes, they feel it is not the same.' Besides providing tailored content, the organisation provides food (dinner for the evening shift, and light breakfast for morning shift) for parents and their children who attend classes and childcare, so stay-at-home mothers are more likely to enrol in the program (Fieldnotes, 15 September 2015).

Through ;TechComunidad!, Musel-Guilley intended to achieve at least two simple technology abilities: (a) for parents to have complete mastery of email, and (b) for them to know how to use search engines. Besides computer and internet skills, ¡TechComunidad! had a larger goal of educating parents about helping their children have better prospects for work and social inclusion through technology. In this sense, the program is consistent with community informatics goals: to focus on community needs first and foremost, and to integrate technology training and use to focus on those community needs (Gurstein, 1999). Throughout the program, she made sure the instructors asked parents to bookmark weblinks that could help parents with their children.

In a personal communication, Musel-Guilley explained how in 2007 she was an integral part of an innovative learning fair hosted by Austin Independent School District (Austin ISD). They had never had an event that targeted Spanish-speaking parents. Their focus was to link organisations and non-profits with the parents so they would be better able to guide their children from pre-kindergarten to college. She thought it was important because growing up, she believed that the more parental involvement there was, the more likely the student would succeed. She felt that any program that only focused on the youth would be missing out on the parents.

Musel-Guilley always had a passion for technology, and in traveling across many large cities in the United States of America with a version of the learning fair, she could see that the program was going to change families and their lives, but many of the parents could not grasp technology. Musel-Guilley learnt that although they had put a lot of energy into such events, with numerous entities trained on how to target/market Spanish-speaking families, the events lacked two essential elements: families needed technology access and information, and training about how to use computers and the internet.

Musel-Guilley realised then the organisation needed to educate parents about technology. It was important for her to target those families that do not know how to turn on a computer. She felt strongly about building children's education for increased skills. A local Texan tech and computer manufacturing company gave the organisation 
the opportunity to work with them because they saw that ;TechComunidad! would be different and innovative, and it would also create a partnership.

\section{Selection Criteria for ; TechComunidad!}

To participate in the program, parents needed to be selected and approved through a two-step process: the completion of an application and a face-to-face interview. The criteria for selection included being a resident in a specific zip code and being a parent of children between the ages of five and 17. There was an exception for grandparents who lived together with their grandchildren and were their caregivers. They could not have a computer at home. However, the majority of the parents had smartphones and used the internet on their mobile devices. Most of the parents had e-mail and Facebook on their smartphones, although several did not remember their passwords and were unable to access their emails on computers. This group of parents was very mobile phone-oriented. For example, throughout the classes, several parents said they had never seen a Facebook page on a computer.

At the end of the training, parents had to take a final exam, indicating that they had mastery over basic technology skills, which included using an online search engine, using an email account, and using the cloud to store files. The parents were required to attend a graduation ceremony where they were given a computing device with internet access capability. In the past years, it was a tablet, and since 2014, it has been a Samsung Chromebook - a computer based on an operating system by Google that works only with internet connection and is based on the concept of cloud computing.

\section{Findings}

To respond to the question: How is education and technology integrated into the program, we organised our findings of the curriculum of ;TechComunidad! into three large categories: (a) Basic Internet skills, (b) Monitoring Skills, and (c) Device Skills (see Figure 1). Before discussing these, it is crucial we start with the sessions before the formal classes. Parents were part of an orientation and a motivational talk, where Musel-Guilley, the founder of the program, delivered in English, and instructors translated it into Spanish simultaneously.

The orientation class was about informing parents of the attendance rules and the logistics of the program, such as childcare and youth classes for their K-12 children (Fieldnotes, 11 November 2015). ;TechComunidad! in the evenings also provided educational activities for the participants' children. Those who achieved perfect attendance were told that they would enter a raffle with the chance to win a laptop given by the local Texan tech company. It was during the orientation session that parents were surveyed about their tech knowledge and skills, so ;TechComunidad! could be organised into group levels. Participants were asked if they had an email account, if they used it, if they had a computer at home, which social media websites they used, if they currently used the internet, if they had smartphones with data plans, and if they had the internet at home. 
The motivational talk, we argue, was responsible for initially setting-up the technodisposition for this group of parent-students that was contextually grounded in the city of Austin, Texas, and the state itself. In this session, Musel-Guilley asked the parents (mostly mothers) if they knew how many universities were in Texas, and what it took to become a student in them. She went on to explain that only the top $7 \%$ of high school students would make it, to which she added: 'How are you going to help them? They will need your help!' (Fieldnotes, 18 November 2015).

She also talked about how Austin is 'an epicentre of technology' or 'a technology hub' by providing and showing examples on a projector of Austin start-up companies (e.g., Monster project). Musel-Guilley challenged the parents in the room by saying that they should not ask their daughters or sons for help. In the same occasion, she said: 'We don't want you to go to them to ask for help' after asking: 'How many of you can help your children to get into the university system?' (Fieldnotes, 18 November 2015).

Musel-Guilley also showed compelling examples of tech job offers in Austin by showing a number of news articles, explaining that 'less than $2 \%$ of all Texas high school students are taking a computer science [class]' and thus there is a high demand from tech companies for a qualified workforce. In order to show the impact, she also talked about how much the participants' children could earn if they choose a tech career: 'They could earn $\$ 57$ per hour or $\$ 117,000$ per year.' (Fieldnotes, 18 November 2015).

iTechComunidad!'s founder also emphasised the content as she said, 'We will cover sophisticated subjects, we have to because of the device we'll give to you.' She introduced the concept of cloud computing and explained how the cloud is a place that is online, an invisible network that enables computers to talk to each other. Throughout her talk, she made statements such as 'we want you to have the latest device' or 'technology makes Austin special' (Fieldnotes, 18 November 2015).

On top of offering a context, Musel-Guilley also went over the differences among tablets, laptops and smartphones. She showed the participants the three devices and went over what can be done with them. She also covered the advantages of a computer and software not available through Chromebooks. This compact session served its purpose of motivating parents, and above all, instilled the significance of techno-capital in their lives as low-income and low-education parents with children who have the opportunity of attending higher education.

\section{Learning basic internet skills}

iTechComunidad! deliberately targeted the $8 \%$ of Austinites who appeared to have little-to-no skills with ICTs and no access to broadband internet at home (Strover et al., 2015). In fact, the screening interviews to get into the program tried to screen out those who already had access, or knew quite a bit already, in order to concentrate on the most needy. To help address this lack, early in the program, parents created an e-mail account with Google, learnt to change the language setting of Google Chrome to Spanish, and acquired the vocabulary to differentiate between browsers and search engines, as well as 
learning to use key websites, like the school district website that allowed parents to monitor their children's attendance and grades. This activity brought an enthusiastic response from the parents, who often did not know how their children were doing in school.

Essentially, iTechComunidad! sought to equip parents with basic internet skills. One student, in her extra-credit assignment, remarked that her interviewee was able to reconnect with family members thanks to her ability to use e-mail. Another noted:

One other thing that Maria learned was how to search for a doctor, dentist, etc. for her children...Google searches for places nearby and also gives her additional information like what language the doctor use...'

These basic internet skills, while pedestrian for most Millennials and younger cohorts, can engender techno-dispositions and techno-capital that enhance, motivate, and create awareness about ICTs and quality of life as it relates to communication, health, business, and education for Spanish-dominant Latinos who find themselves in the digital divide.

Developing the skill sets in the areas mentioned above and technologies, as most participants put it on their typed essays, have become knowledge necessities. Not so much for catching-up with the technological arena of the $21^{\text {st }}$ century but for its cultural capital value. That is, being able to take classes about handling computers and the internet can open up the possibilities for Latino participants to widen their cultural capital, such as learning and improving their English competence through apps and open-source computer software. On one essay entry, a participant wrote:

She plans now, thanks to the knowledge that she acquired, to have a better job so she can use what she learned and to have a better quality of life for her family and be a better person in the community. From now on, she will continue using the programs to better her English, because her dream is to be bilingual.

Eventually, the techno-disposition being created through basic internet skills was one that transformed techno-capital into other types of cultural capital. For instance, after the training, mothers frequently went home and persuade their husbands to invest in an internet connection, so that their children could do their homework better and more easily. Interviews with librarians over several years at the library near the non-profit organisation showed that many children and youth went to that library to do their homework. This was because their parents did not have internet connectivity or a computer at home.

\section{Monitoring skills through ICTs}

As iTechComunidad! advanced, so did the harbouring of internet skills. One clear goal of iTechComunidad! was to help develop the care about and desire for the educational advancement of the participants' children. Creating an e-mail account was the first step 
for parents to be able to contact their children's teachers and to sign-up for the parentcloud system of Austin ISD. The next step was to familiarise parents with its website and set-up the account by linking their e-mail to it. Now, parents were able to get updates about their children in regard to conduct, absences, grades, and any deadlines the school had for the submission of forms or registration. Having an e-mail that was easy to access meant that parents could communicate with teachers from home. It saved them time. One parent-student noted from her interview with, and essay about, another:

Maria, like me, had never used a computer before. She didn't know how to turn it on or off, and even less, how to navigate the Internet (...). Now, Maria can be up-to-date about the grades of her children with only click. Before, Maria had to go the school and ask them for their grades, or wait until it was time for teachers to send the grades home (...). She can send an e-mail to communicate with teachers without interrupting classes.

Time-saving practices involving children, as well as not feeling guilty for interrupting teachers, suggest education-oriented techno-capital is valued by the parents, nearly all mothers. While this kind of monitoring of schooling is very valuable in the overall social mobility of the families (Bertaux \& Bertaux-Wiame, 1997), it does show that these concerns are gendered alongside motherhood lines.

The advantages of ICTs in their children's education did not stop after parents learnt to use e-mail or access websites like the school district Parent Cloud. Later in the course, parents learnt about storing and organising photos, creating text documents in Google drive, using Google calendar, and downloading free educational video games through the Chrome or Play store. Parents came to understand these as 'new sites of learning' through Google online products. Helping their children now became an interactive activity that involved the search for and use of multiple resources with more steps (like cutting, pasting, storing, linking) to complete a homework assignment. Through iTechComunidad!, parents learnt 'how to find free programs to help me create all types of documents, letters, flyers, posters and pamphlets.' Google Calendar was also seen as 'practical, because you can add events, conferences, and homework because you can add the hour, date, and place for each school event in order to stay update with your children.'

On their essays, parents frequently wrote about both their and other parents' increased confidence in helping their children become 'good students' who will essentially go to college, as a result of the ;TechComunidad! course. Parents tended to gain a good sense of how to guide the schooling of their children and their own know-how, or technocapital, of digital techniques (like e-mail and taking advantage of Google drive) to feel competent, proud, and assertive.

In an interview with one woman before she took the class, she said she felt like she was 'the only dumb one' at home, since her husband at least knew how to use the internet on a mobile phone, and her children were already digitally literate from school. iTechComunidad! enabled her to feel more knowledgeable and confident with technology. The techno-disposition created here was one that married personal and technological fulfillment with a parental desire for upward social mobility to feel active 
in helping their children's educational attainment. When it comes to shaping technocapital, this techno-disposition does so by instilling the idea that parental self-esteem as well as knowledge is significant in matters involving the participants' children, ICTs, and education.

\section{Device skills (how to operate their Chromebook)}

The parents were trained on Google Chromebooks in part because Google was one of the major sponsors of the program. The organisation cooperated with Google in helping promote sign-ups for Google Fiber ${ }^{5}$, a fibre-optic internet and television service, in the neighbourhood, for which they received free connectivity for the organisation. The parents were also promised a Chromebook to take home if they graduated. Interviews, during the selection process, showed that the promise of earning a computer was a major motivating factor for some people to complete the course. Our results show that the organisation created a positive techno-disposition among the parents by delivering information about the latest technological concepts such as cloud computing. The Chromebook device, which the participants started using in Lesson 1, had the parentstudents' own names labelled on them. However, they were told that we would be given the device only by the end of the training after attending the classes (they were allowed to miss only two classes) and passing an exam. Prior to that, parents had to return their Chromebooks after each class.

Before the launch of ;TechComunidad!, the organisation had had its own computer lab filled with local Texan tech company desktop computers as well as laptop computers. However, the directors of the organisation felt that learning on 'their own' computer would help motivate the participants. This choice seems to have been a good approach according to our qualitative data. Right from the start of iTechComunidad!, parents knew they were using the latest device, which required covering 'sophisticated subjects'. This section of the training encompassed learning about Google products that could be used on the Chromebook such as Google docs, Google drive, and Google calendar. One parent noted on her written assignment:

As they taught me, with a Chrome I can use my applications without having to use a hard disk because Google has created a new program to store in the air and it is safer and without risks of losing the information its name is called (the cloud).

Parents also learnt how to operate the camera in the Chromebook and how to take snapshots. Given the strong emphasis in learning about Google products and software, some parents began to call themselves 'chromies' which the instructor introduced in the class during the teaching of Lesson 4.4. Such individual is defined in the handout 'a Google enthusiast who owns a Chromebook and who operates their daily life and business with Google Apps and a Chromebook device'. One of the parents when writing her extra-credit project wrote:

5 See more at https://fiber.google.com/intl/es/cities/austin/ 
We are pleased with the achievements of valuable and enterprising women in our Hispanic community. Thanks to ¡TechComunidad!, we will not lose the focus of taking advantage of all the resources available to us, we will be able to become chromies.

There is also an empowering effect of using the latest device in the way the participants understand how iTechComunidad! impacted their lives and their use of technology. Besides highlighting several good takeaways of the training, one parent wrote about what her colleague had said about ;TechComunidad!: Thanks to this course you can say that you have changed your life in a drastic way by the simple fact of having learned to use a GOOGLE-CHROME computer. This comment, and specially the use of the term 'simple facts', illustrates how these parents may feel better empowered in a Technopolis by being able to use cutting-edge technologies.

\section{Discussion}

It has been postulated that the relationship between techno-capital and technodispositions is a complex one (Lee \& Chen, 2016; Lu \& Straubhaar, 2014; Straubhaar et al., 2012), and we also find that the associations among techno-dispositions is equally intricate and relational. Three techno-dispositions were discussed and conceptualised in regard to ;TechComunidad! and its digital inclusion efforts with these Latino/a parents, analysed in this study (see Figure 1). First, technology was useful and relevant tool for all the parents and children (basic skills). Second, technology could help parents track and help their children's performance (monitoring skills). And third, parents realised that they could understand and use technology, that they did not have to be 'dumb' while everyone was smart about it (device skills). While there might be a starting point in teaching computer skills and orientations, techno-dispositions are not necessarily linear or chronological. Most parents admitted that their handling of computers/ smartphones was not the best in taking full advantage of the websites/applications they accessed. It was the decision of the community technology centre to first harness basic internet skills coupled with talks about the benefits of these skills to parents. Then, parents were given their Google Chromebook to practice on, learn from, and experiment with applications, websites, and services that could be crucial in the educational attainment of their children. Digital education was therefore complimentary and simultaneous, as illustrated in Figure 1. So, as parents learnt about the Parent Cloud system, they also learnt about how to access it on their computer, enhancing both an awareness of services that were important to them and the device itself. It is thus hard to pinpoint and delineate a proper progression of techno-dispositions, for these are highly inter-dependent. In order to highlight a few ideas, this discussion will be organised into four subsections.

\section{Goals and Aspirations}

¡TechComunidad! has laid out its goals since its orientation. It was imperative for the class to help parents with the education of their children using and handling ICTs. Our analysis of the lesson plans of iTechComunidad!, in addition to what parents wrote about their fellow students, strongly suggests that this objective was successfully met. 
Thanks to ;TechComunidad!, parents were not only able to develop the techno-capital and techno-dispositions to guide their children scholastically but themselves too. Many expressed in their essays a desire to learn English, to continue with their education, or the possibility of advancing at work. Through these aspirations, and in some occasions actual achievements, ;TechComunidad! fulfilled its second goal - to improve the quality of life for parents and their families. Having a curriculum that prioritises education, while culturally significant in fostering social mobility, may possibly restrict the technodispositions of parents. We see it as possibly limiting, because overcoming the digital divide is a matter of expanding techno-capital to a variety of digital skills including creative uses of the internet and computers. Also, unlike other digital inclusion programs involving parents (e.g., Machado-Casa, Sánchez \& Ek, 2014), iTechComunidad! lacked parent-and-child together lessons, which could have been useful in identifying children's needs from their perspective. The classes could thus run the risk of becoming a strict top-down educator, making it difficult to consider community needs outside the ones previously laid out. The organisation offers a number of classes, after-school programs and summer camps with youth, including a very substantial focus on helping them think through and set personal and career goals. Afterwards, they link those goals to the education required to reach them.

\section{Adoption of Language}

The results from this study suggest that the acquisition of techno-capital and technodisposition is also fostered through the teaching and adoption of a language that denotes a sense of belonging to a community of Chromebook users and Google products. The self-presentation of themselves as chromies show that some of these parents incorporated slang terms that have been created around a specific device, a specific technology, which gives them a sense of pride, as they were said they were learning 'sophisticated technology.'

In fact, chromies is part of a larger phenomenon called by USA education leaders as the Googlification of education. Although the research about this effect is still scant, according to the New York Times, Chromebooks account for more than half of all devices shipped to USA's K-12 schools (Singer, 2017). That represents huge growth for Google and some decline for Apple as the computer that children learn from at school. Like the participants from ;TechComunidad!, more than 30 million students - more than half of all those in the USA - use free Google apps, such as Docs or Gmail, in the classroom. The debate around this phenomenon has to do with the goals of the company behind the donation of Chromebooks to schools, or in the case of this article, to digital inclusion programs. Is it to get more people hooked on its products and services earlier in life? This has led to the questioning of Chromebook usage in classrooms around the United States of America. Some have looked at it with scepticism and caution (Singer, 2017). While some of the ;TechComunidad! participants may feel a sense of pride and belonging in being chromies, drawing on the debate around Googlification, we argue that in order to expand techno-dispositions, programs like iTechComunidad! should include a lesson about other technologies. In the orientation session, however, the participants are briefly told that there are advantages of having a computer, other than a 
Chromebook, that allows the user to have a broader range of software (Fieldnotes, 16 February 2016).

\section{Connectivity to a larger community}

One particular problem with Chromebooks that emerged after the training was that many graduates of the program still did not have internet access at home. Since the Chromebook is almost entirely dependent on accessing online software to let the user get access to both programs and data, it is not very useful without connectivity. In fact, follow-up interviews by the lead researcher with past participants after the program showed that a number of the Chromebooks were sitting in a closet, for lack of broadband at home. Many of the women felt they had learnt quite a bit, but they were back to using smartphones as their main device instead of computers. That tendency was reinforced by social capital, since many of their friends primarily used smartphones, and it was easy to fall back into the larger habitus (Bourdieu, 1984) or pattern of the people they associated with in the neighbourhood. While these parents gain techno-dispositions, they may face what Gonzales (2016) argues is a shift in the USA digital divide from issues of ownership to issues of sustainability. These parents were granted a device that operates only with internet, but they might struggle to maintain stable access to home broadband internet. Along these lines, perhaps what is missing here is an investment in technology maintenance practices, ensuring that these parents can have sustainable access to the internet and technology.

Despite the limitations of the Chromebook, a Googlified curriculum, and the difficulties of technology maintenance problems, the participants of this program benefited in acquiring techno-dispositions from the context-bound training, in learning how to navigate the Parent Cloud, to check their children's grades online, how to access informational websites in their native language such as the Univisión website and the New York Times website in Spanish. One of the factors that influences technodispositions is geographic location (Straubhaar et al., 2012). The neighbourhood where the organisation is located is, in some ways, a classic example of an ethnic enclave. In fact, some women, particularly those less educated housewives, interviewed early in the project, were afraid to drive out into the rest of the city, because they were not familiar with it and because many people outside did not speak Spanish. One benefit of the program was to help them feel more a part of the larger city, particularly the school system, through use of the Austin ISD Parent Cloud website ${ }^{6}$.

\section{Teaching Challenges}

One of the biggest challenges for teaching the program participants was explaining the difference between a browser (e.g., Google Chrome, Safari, and Firefox) and a search engine (e.g., Google, Bing, and Yahoo). This difficulty was related primarily to the similarity of names, since the only browser participants had on their devices was Google Chrome, and the search engine most used was Google. Being confused about the two could also be explained by the fact that most of the participants were mobile

\footnotetext{
6 See here: https://www.austinisd.org/technology/parents-guardians/cloud
} 
phone users, therefore not used to going online via a browser. The curriculum did not include an extensive explanation of the difference between the internet and the web. Furthermore, this learning difficulty could have arisen due to the generational gap among iTechComunidad! participants, because older parents or grandparents needed more time and repetition to learn than younger parents. It also did not help that many of these older parents or caregivers were not smartphone owners. Eight weeks of computer course (with cloud computing concepts) was possibly not enough for the older participants to grasp certain concepts such as search engines and browsers.

Finally, some trends in our work merit closer attention. First, there is a possibility for gendered techno-dispositions to ensue from community classes about computers and the internet. Past research found that men do not only outnumber women users in public libraries, but men associate these spaces with technology while women expressed 'library nostalgia' that did not include technology, and were likely to be technophobic, especially older women (Dixon et al., 2014). The parent-students in ;TechComunidad! were not only predominantly (Latina) women, but they also seemed to value the class for helping them be better connected, widening their communication venues, and be able to perform nuanced research online. Secondly, one of the future goals of iTechComunidad! is to transform some of those parents or mothers into active community/technology mentors, in order to reach more easily those $8 \%$ of adults who do not use the internet in the Technopolis studied in this article. This, if achieved, would be another level of digital literacy effort, with a bottom-up and cultural approach. Several parents expressed an interest in participating on their intake forms used during the selection process for iTechComunidad!. These mentors would be further incentivised and rewarded with a stipend by the organisation. We are left wondering how this will be achieved, and more so, how ICTs will be involved. Future research should consider studying how parents (mostly mothers) transition from graduates to technology instructors and mentors for other community members, and the strategies that CTCs use in producing them.

\section{Conclusions}

This article has two particularly important sets of conclusions that may have implications to policymakers and curriculum creators of digital inclusion programs, such as iTechComunidad!. Based on the material covered in iTechComunidad!, the computer took centre stage as opposed to ICTs that parents already knew and perhaps were more comfortable in using. For digital inclusion curriculum creators, it might be worth thinking about how to integrate the technology that the parents already have, usually basic smartphones with some kind of minimal connectivity, into the training so the parents also become more proficient with the technologies that they are already using the most. In a parallel program in the same city, one of the authors observed that older learners bring in their smartphones to training and put them down next to the computer, hoping to leverage what they already know on the smartphone to what they are trying to learn on the computer.

It is worth highlighting again that technology education for the parents is undertaken in the context of a Technopolis. Parents are being encouraged to learn about technology 
primarily so that they could help their own children in school. This was done after a careful assessment by the program founder that technology education for children and youth was not enough without including their parents. The organisation decided to focus on the techno-disposition of both youth and parents to learn technology for a specific, practical reason: to improve their ability to do well in school or workforce training, and to learn technology skills that would enhance that.

And finally, the other set of conclusions concern the critical importance of educating working class USA Latino/a parents in two different kinds of material. First, it is the importance of helping them understand the changing nature of the job market in the USA, particularly in technology-oriented cities like the one in which they live. Related is helping them understand the importance of completing high school, specialised skill education, or college education for their children. The program examined here literally starts the parents' education with two full days on these topics, setting an agenda or working to increase the parents' dispositions and cultural capital toward seeing these issues as important.

\section{Acknowledgments}

The authors of this article are thankful for the River City Youth Foundation, where this study was carried out. We also acknowledge the participants of TechComunidad. The first author also thanks the Portuguese funding agency FCT (Fundação para a Ciência e Tecnologia), as during the initial phases of this project, she had a doctoral scholarship under the grant SFRH/BD/51304/2010. 


\section{References}

River City Youth Foundation. (n.d.) About. Retrieved from http://rivercityyouth.com/about/

Austin Chronicle (2014, April 11). Dove Springs: A Demographic Snapshot. Retrieved from https://www.austinchronicle.com/news/2014-04-11/dove-springs-a-demographicsnapshot/

Balboni, M. R. (2007). Por detrás da inclusão digital: uma reflexão sobre o consumo e a produção de informação em centros públicos de acesso à Internet no Brasil (Doctoral dissertation, Universidade de São Paulo). Retrieved from http://www.teses.usp.br/teses/ disponiveis/27/27154/tde-10102007-120815/en.php

Bertaux, D., \& Bertaux-Wiame, I. (1997). Heritage and its lineage: A Case History of Transmission and Social Mobility over Five Generations. In D. Bertaux and P. Thompson (Eds.), Pathways to social class: a qualitative approach to social mobility (pp. 62-97). New York: Oxford University Press.

Bourdieu, P. 1984. Distinction: A social critique of the judgment of taste. Cambridge, MA: Harvard University Press.

Büchi, M., Just, N., \& Latzer, M. (2016). Modeling the second-level digital divide: A fivecountry study of social differences in Internet use. New Media \& Society, 18(11), $2703-2722$.

Cunningham, C. M. (2009). Technological learning after school: a study of the communication dimensions of technological literacy in three informal education programs for female and minority youth. (Dissertation, University of Texas). Retrieved from https:// repositories.lib.utexas.edu/handle/2152/17296

Dúran, R., Dúran, J., Perry-Romero, D., \& Sanchez, E. (2001). Latino immigrant parents and children learning and publishing together in an after-school setting. Journal for Students Placed at Risk, 6, 95-113. doi: 10.1207/S15327671ESPR0601-2_6

Ginossar, T., \& Nelson, S. (2010). Reducing the health and digital divides: a model for using community-based participatory research approach to e-health interventions in lowincome Hispanic communities. Journal of Computer-Mediated Communication, 15(4), $530-551$.

Gurstein, M. (Ed.). (1999). Community Informatics: Enabling Communities with Information and Communications Technologies. Hershey: IGI Global.

Hargittai, E., \& Walejko, G. (2008). The participation divide: Content creation and sharing in the digital age. Information, Community and Society, 11(2), 239-256.

Hilbert, M. (2016). The bad news is that the digital access divide is here to stay: domestically installed bandwidths among 172 countries for 1986-2014. Telecommunications Policy, 40(6), 567-581.

Katz, V. S. (2010). How children of immigrants use media to connect their families to the community. Journal of Children and Media, 4(3), 298-315. doi: $10.1080 / 17482798.2010 .486136$

lalorek (2016, May 19). Google Gives Grants to Austin Public Library Foundation for Digital Inclusion Program. Silicon Hills, Technology News about Austin and San Antonio. Retrieved from http://www.siliconhillsnews.com/2016/05/19/google-gives-grants-toaustin-public-library-foundation-for-digital-inclusion-program/

Lentz, R., Straubhaar, J., Dixon, L., Graber, D., Spence, J., Letalien., B., \& LaPastina, A. (2012). Structuring access: The role of Austin public access centres in digital inclusion. In J. Straubhaar, J. Spence, Z. Tufekci, \& R. G. Lentz (Eds.), Inequality in the 
technopolis: Race, class, gender, and the digital divide in Austin (pp. 165-192). Austin: University of Texas Press.

Lopez, M. H., Gonzalez-Barrera, A., Patten, E. (2013). Closing the digital divide: Latinos and technology adoption. Washington, DC: Pew Hispanic Center.

Lu, C., \& Straubhaar, J. D. (2014). The influence of techno-capital and techno-disposition on college-going processes of Latina/o college students in Central Texas. Learning, Media and Technology, 39(2), 184-198. doi: 10.1080/17439884.2013.782039

Lutz, C. (2016). A social milieu approach to the online participation divides in Germany. Social Media+ Society, 2(1), 2056305115626749.

Machado-Casa, M., Sánchez, P., Ek, L. D. (2014). The digital literacy practices of Latina/o immigrant parents in an after-school technology partnership. Multicultural Education, 21(3-4), 28-33.

McConnell, C. L. (2014). Digital Inclusion and Techno-Capital in Austin, Texas (Unpublished dissertation). The University of Texas at Austin; Austin, Texas.

Norris, P. (2001). Digital divide: Civic engagement, information poverty, and the Internet worldwide. Cambridge University Press.

Radovanović, D. (2012). Digital Divide and Social Media: Connectivity Doesn't End the Digital Divide, Skills Do. Available at SSRN: https://ssrn.com/abstract=2001952 or http:// dx.doi.org/10.2139/ssrn.2001952

Rivera, H. (2008). Bridging the technology gap for low-income Spanish-speaking immigrant families. Association for the Advancement of Computing in Education Journal, 16(3), 307-325.

Rojas, V., Straubhaar, J., Spence, J., Roychowdhury, D., Okur, O., Piñon, J., \& Fuentes-Bautista, M. (2012). Communities, cultural capital, and digital inclusion: Ten years of tracking techno-dispositions and techno-capital. In J. Straubhaar, J. Spence, Z. Tufekci, \& R. G. Lentz (Eds.), Inequality in the Technopolis: Race, class, gender, and the digital divide in Austin (pp. 223-264). Austin: University of Texas Press.

Servon, L. J., \& Nelson, M. K. (2001). Community technology centres: Narrowing the digital divide in low-income, urban communities. Journal of Urban Affairs, 23(3-4), 279-290.

Singer, N. (2017, May 13). How Google Took Over the Classroom. The New York Times. Retrieved from https://www.nytimes.com/2017/05/13/technology/google-educationchromebooks-schools.html

Straubhaar, J., Spence, J., Tufekci, Z., \& Lentz, R. G. (Eds.) (2012). Inequality in the technopolis: Race, class, gender, and the digital divide in Austin. Austin, Texas: University of Texas Press.

Strover, S., Straubhaar, J., Gustafson, K., Chen, W., Shrubbe, A., \& Popiel, P. (2015). Digital inclusion in Austin: Results from a citywide survey. Austin, TX: Technology and Information Policy Institute.

Tondeur, J., Sinnaeve, I., Van Houtte, M., \& van Braak, J. (2011). ICT as cultural capital: The relationship between socioeconomic status and the computer-use profile of young people. New Media \& Society, 13(1), 151-168.

Tsei, E., \& Rains, S. A. (2017). Smartphone Internet access and use: Extending the digital divide and usage gap. Mobile Media \& Communication, 5(3), 239-255. doi: $10.1177 / 2050157917708329$

Gonzales, A. (2016). The contemporary US digital divide: from initial access to technology maintenance. Information, Communication \& Society, 19(2), 234-248. 
van Dijk, J. A. (2006). Digital divide research, achievements and shortcomings. Poetics, 34(4-5),

Yin, R. K. (1989). Case study research: Design and methods, revised edition. Applied Social Research Methods Series, v5. Thousand Oaks, California: Sage Publications. 